\title{
Heart-hand syndrome
}

INSERM

\section{Source}

INSERM. (1999). Orphanet: an online rare disease and orphan drug data base. Hearthand syndrome. ORPHA:228184

Heart-hand syndrome refers to a group of congenital disorders characterized by malformations of the upper limbs and heart. To date, heart-hand syndrome comprises the following rare syndromes; Holt-Oram syndrome; heart-hand syndrome type 2; hearthand syndrome type 3; heart hand syndrome, Slovenian type, brachydactyly-long thumb; and patent ductus arteriosus-bicuspid aortic valve - hand anomalies (see these terms). 